\title{
A Case Crossover Analysis of Out-of-Hospital Cardiac Arrest and Particulate Matter Air Pollution: Investigation of Specific Subgroups
}

\author{
Marie Albert ${ }^{1}$, Mohamed Lemdani1 ${ }^{1}$ Damien Cuny' ${ }^{2}$, Patrick Duriez ${ }^{3}$, Joséphine Escutnaire ${ }^{1,4}$, \\ Pierre-Yves Gueugniaud ${ }^{4,5}$, Eric Wiel ${ }^{1,6}$, Hervé Hubert ${ }^{1,4}$, Christophe Di Pompeo ${ }^{1,4}$ \\ ${ }^{1}$ Public Health, Epidemiology and Healthcare Quality, The University of Lille, Lille, France \\ ${ }^{2}$ IMPECS-Impact of the Chemical Environment on Human Health, The University of Lille, Lille, France \\ ${ }^{3}$ INSERM U1171, Degenerative and Vascular Disorders, Faculty of Medicine Lille, The University of Lille, Lille, France \\ ${ }^{4}$ French National Out-of-Hospital Cardiac Arrest Registry Research, RéAC, Lille, France \\ ${ }^{5}$ SAMU 69 and Emergency Department, Lyon University Hospital, Lyon, France \\ ${ }^{6}$ SAMU du Nord and Emergency Department for Adults, Lille University Hospital, Lille, France \\ Email: marie.albertthananayagam@univ-lille2.fr
}

How to cite this paper: Albert, M., Lemdani, M., Cuny, D., Duriez, P., Escutnaire, J., Gueugniaud, P.-Y., Wiel, E., Hubert, H. and Di Pompeo, C. (2017) A Case Crossover Analysis of Out-of-Hospital Cardiac Arrest and Particulate Matter Air Pollution: Investigation of Specific Subgroups. Open Access Library Journal, 4: e4143.

https://doi.org/10.4236/oalib.1104143

Received: November 10, 2017

Accepted: December 4, 2017

Published: December 7, 2017

Copyright $\odot 2017$ by authors and Open Access Library Inc.

This work is licensed under the Creative Commons Attribution International License (CC BY 4.0).

http://creativecommons.org/licenses/by/4.0/

\begin{abstract}
There is increasing evidence of association between particulate matter air pollution and cardiovascular mortality and morbidity. However, the association with the out-of-hospital cardiac arrest (OHCA) event is less clear. We investigated the effects of short-term particulate matter exposure on OHCA especially among specific subgroups. The study included OHCA that occurred in the Nord-Pas-de-Calais region, France, in 2015. A time-stratified casecrossover study design coupled with a conditional logistic regression was used to evaluate the association between OHCA and particle levels of 10 or $2.5 \mathrm{mi}-$ crometers or less (PM10 or PM2.5 respectively) measured within the hour of the arrest up to 5 days before. Susceptible subgroups by sex, age, diabetes status among OHCA that occurred during non-holiday periods were investigated. In all, 1039 cases were included. Significant associations were found between OHCA during non-holiday periods and PM2.5 and PM10 exposure four days before the arrest and on the day of the arrest. The largest OR were found for the cumulative average twelve hours before the arrest of PM2.5 (OR $=1.17, \mathrm{p}=0.016)$ and PM10 $(\mathrm{OR}=1.33, \mathrm{p}<0.001)$. With PM2.5, larger OR with smaller $\mathrm{p}$-values were generally obtained within the subgroups of men, age 50 to 75 years old and cases with diabetes. The findings show a significant link between short-term exposure to particulate matter and OHCA during non-holiday periods, with susceptible subgroups to PM2.5 (men, age 50 to 75 years old and diabetics).
\end{abstract}




\section{Subject Areas}

Epidemiology, Public Health

\section{Keywords}

Sudden Death, Heart Arrest, Epidemiology, Particulates, Pollution

\section{Introduction}

Cardiac arrest is an important public issue. Overall survival rates remain low in most countries but vary widely across the world where it is expected to range from $2 \%$ to $20 \%$ [1]. In the general population, the incidence of sudden cardiac death (SCD) would be in the range of $4-5$ million cases per year [2]. In France, it is estimated at 50,000 cases per year, more than $85 \%$ of which occurring outside of a hospital setting [3]. Although the incidence of SCD increases with age, the proportion of deaths that are sudden is larger in the younger age groups in which the socioeconomic impact of SCD is greater [4].

Air pollution is the fourth highest-ranking risk factor for death globally and was estimated to cause 5.5 million deaths worldwide per year in 2013 [5]. Shortterm exposure to air pollution especially with regard to fine particulate matter is increasingly associated in the literature with cardiovascular morbidity and mortality [6] [7] [8] [9] [10]. A positive association can be found between fine particulate matter with an aerodynamic diameter under $2.5 \mu \mathrm{m}$ (PM2.5) and out-ofhospital cardiac arrest (OHCA) in several studies [11] [12] [13], though the association is insignificant in others [14] [15]. With respect to PM smaller than 10 $\mu \mathrm{m}$ (PM10), carbon monoxide (CO), sulfur dioxide $\left(\mathrm{SO}_{2}\right)$, nitrogen dioxide $\left(\mathrm{NO}_{2}\right)$ and ozone $\left(\mathrm{O}_{3}\right)$, the evaluation of risk of OHCA leads to inconsistent results [13] [16] [17] [18].

The aim of our study is to investigate the effect of exposure, at hourly and daily scales, to particulate matter (PM2.5 and PM10) on the incidence of OHCA in Nord-Pas-de-Calais (NPdC), France. Additional objectives were to investigate, among OHCA occurring over non-holiday periods (as pollution levels are different between holiday and non-holiday periods), the effect in specific subgroups by sex, age and diabetes status so as to reveal potentially vulnerable subgroups that would incite public authorities to review air quality standards.

\section{Materials and Methods}

\subsection{Out-of-Hospital Cardiac Arrest Data}

From January 1 to December 31 2015, OHCA data that were recorded by ten mobile emergency and resuscitation services were collected from the French cardiac arrest registry "Registre électronique des Arrêts Cardiaques" (RéAC) for a population representing $71.45 \%$ of the 4.2 million inhabitants of the NPdC re- 
gion. The RéAC is an electronic, web-based data management system that includes patients of any age who have had an OHCA with a mobile medical team involved [1]. The RéAC form is structured according to the Utstein universal style which has been the recommended guideline for uniform data reporting of OHCA [19]. The form contains, among others, the following categories: socio-demographic data (e.g. sex, age, GPS coordinates of the arrest, the city they live in), schedules and time intervals and the cardiac arrest history (e.g. diabetes status). The registry was approved as a medical assessment registry without a requirement for patient consent by the French advisory committee on information processing in health research (CCTIRS) and by the French National Data Protection Commission (CNIL, authorisation number 910946). Data extracted in NPdC, in 2015 consisted of 1408 cases. We excluded 235 arrests with an etiology inconsistent with the assumption of a pollution related arrest: trauma ( $\mathrm{n}=$ 143), pulmonary aspiration $(n=56)$, poisoning $(n=31)$, drowning $(n=5)$. When the location of the OHCA of the patient was different from the city they live in, the OHCA was excluded $(n=134)$ because of the study design that compares pollution levels to which the patient is exposed within the same month.

\subsection{Ambient Air Quality and Meteorologic Data}

Our study focused on the effect of ambient PM2.5 and PM10 but other regulated gaseous air pollutants $\left(\mathrm{NO}_{2}, \mathrm{O}_{3}, \mathrm{SO}_{2}, \mathrm{CO}\right)$ and temperature levels were also measured for adjustment purposes. The concentrations were measured by gravimetric filter analyses for PM2.5 and PM10, by chemiluminescence for $\mathrm{NO}_{2}$, by $\mathrm{UV}$ absorption for $\mathrm{O}_{3}$, by fluorescence absorption for $\mathrm{SO}_{2}$ and by non-dispersive infrared absorption for CO. Daily and hourly pollutant concentrations over the study period were obtained from 41 stations within the study region under the control of ATMO-NPdC, an association approved by the Ministry of the Environment. For $\mathrm{O}_{3}$, the daily level refers to the 8-hour average daily maximum on the day, in line with the air quality criteria for $\mathrm{O}_{3}$. Daily temperature levels were extracted from 16 stations in the region from Météo France website. For each OHCA, measures from the closest monitor were used as proxies for individual exposure.

\subsection{Study Design}

The case-crossover study design was proposed by Maclure to be applied when brief exposure causes a transient change in risk of a rare acute-onset disease [20]. This can be regarded as a case-control study in which each case serves as his or her own control. The exposure of the patient during the risk period (at the time of the arrest minus the lag time considered to the onset of action) is compared to the distribution of exposure of the patient during a reference period. It has been suggested that exposures during the reference period should be exposures on all days falling on the same day of the week within the same month of the arrest so as to control biases from long-term time trends, seasonal patterns, autocorrela- 
tion in exposures, and day-of-week effects [15] [18] [21] [22]. A risk exposure is then matched with three or four reference exposures depending on the number of times the day of the week occurred within that month. For example, a risk exposure measured on a Sunday in February at 11:00, would be matched with reference exposures measured on all other Sundays at 11:00 in February. This time-stratified case-crossover study design, with reference exposures chosen in the same month of the arrest, controls over personal characteristics that don't vary or vary slowly over time. A case was excluded if any of his or her risk or reference exposure measurement was missing.

\subsection{Subgroups}

After analyzing OHCA occurring all year long, we focused on OHCA occurring during non-holiday periods. Indeed, a holiday effect, defined as differences in air pollutant concentrations between holiday and non-holiday periods, has been reported with higher PM10 levels during non-holiday periods [23]. Holiday periods in 2015 were: from Thursday, January 1 to Sunday, January 4; from Saturday, February 21 to Sunday, March 8; from Saturday, April 25 to Sunday, May 10; from Saturday, July 4 to Sunday, August 30; from Saturday, October 17 to Sunday, November 1; from Saturday, December 19 to Thursday, December 31. A case was excluded if the risk exposure measurement was missing or if less than two non-holiday reference exposure measurements were available. With this scheme, analyses were conducted to evaluate susceptible subgroups of sex, age or diabetes status. The age groups 50 to 75 and over 75 years old were used to make a distinction between seniors and the elderly, following recommendations from the French Center for Strategic Analysis (Centre d Analyse Stratégique) made in June 2010.

\subsection{Lag Times}

In order to take into account a potentially delayed association between the exposure and OHCA onset, each analysis included alternately air pollution exposure concentrations measured at one of the lag times described hereafter. Exposure to air pollution of each case was collected during the hour of the arrest (lag0h); cumulative hourly averages were also computed: CA4h (mean of the hour of the arrest and the three hours preceding the arrest, mean lag0h-lag $3 \mathrm{~h}$ ) and CA12h (mean lag0h-lag11h). Daily lags were also investigated: lag0d (the exposure the day of the arrest) up to lag5d (the exposure five days before the arrest). For the cumulative hourly averages (CA4h, CA12h), values were considered missing if less than $75 \%$ of the hours needed for the average were available.

\subsection{Statistical Analysis}

A conditional logistic regression was used to estimate the odds ratios (OR) providing a measure of the association between air pollution exposure and the oc- 
currence of OHCA. These OR and the corresponding 95\% confidence intervals (CI) were calculated per interquartile range (IQR) increase in pollutant levels, which provide OR estimates that are comparable across the pollutants. As a first model, a single-pollutant model was implemented with the pollutant (PM2.5 or PM10) and with an adjustment for temperature by using a nonparametric smoothing spline of degree 3 with 4 knots optimally chosen [24] [25] [26] [27] [28]. Then, when a lag showed a significant association (OR with a p-value less than 0.05 ), a multi-pollutant model was implemented to check if the association would remain significant after adjusting for potential confounders. The pollutants added in the multi-pollutant models were chosen if they had a moderate correlation (asbsolute value of Spearman correlations, on the day or on the hour of the arrest, between 0.40 and 0.60 ) which would limit confounding and over-fitting. Thus, multi-pollutant models were models adjusted for temperature, $\mathrm{NO}_{2}$ and $\mathrm{O}_{3}$ levels. In each analysis, pollution variables were used with the same lag period; temperature levels were used at lag0d at the hourly scale, and with the same lag period as pollution variables at the daily scale. Investigation of specific subgroups by sex, age and diabetes status was made with single-pollutant models. All analyses were performed using the $\mathrm{R}$ statistical software ( $\mathrm{R}$ Core Team, 2015)

\subsection{Ethics}

This study was done with anonymized patient data, and therefore, ethics committee approval was not necessary.

\section{Results}

Among the 1039 OHCA that met the inclusion criteria, 624 (60.1\%) were experienced by men; $482(46.4 \%)$ patients were in the $50-75$ age group and 423 (40.7\%) patients were over 75 years old; $170(16.4 \%)$ cases have been diagnosed with diabetes. Table 1 provides an overview of air pollution concentrations and temperature data collected for the risk and reference exposures of each case. Absolute values of Spearman correlation coefficients were found between 0.40 and 0.60 with p-values less than 0.001 for: $\mathrm{NO}_{2}$ and PM2.5 $(\mathrm{r}=0.49 ; \mathrm{r}=0.59$ respectively at the hourly and daily scale); $\mathrm{NO}_{2}$ and PM10 $(\mathrm{r}=0.44 ; \mathrm{r}=0.54$ respectively at the hourly and daily scale); $\mathrm{NO}_{2}$ and $\mathrm{O}_{3}(\mathrm{r}=-0.53 ; \mathrm{r}=-0.40$ respectively at the hourly and daily scale). The multi-pollutant models were then obtained from the single-pollutant models (with PM2.5 or PM10) adjusted for $\mathrm{NO}_{2}$ and $\mathrm{O}_{3}$. Conditional logistic regression results at the hourly and daily time frames are summarized on Tables 2-4, and Figure 1 and Figure 2.

No significant association at any lag was found between OHCA occurring all year long and PM2.5 or PM10 (Table 2). The assessment of the association between non-holiday OHCA and PM2.5 (Table 3) showed significant associations for both single- and multi-pollutant models at lag0h, CA4h and CA12h where the OR peaked $(\mathrm{OR}=1.17, \mathrm{p}=0.016)$, and in addition for single-pollutant models 
Table 1. Description of data.

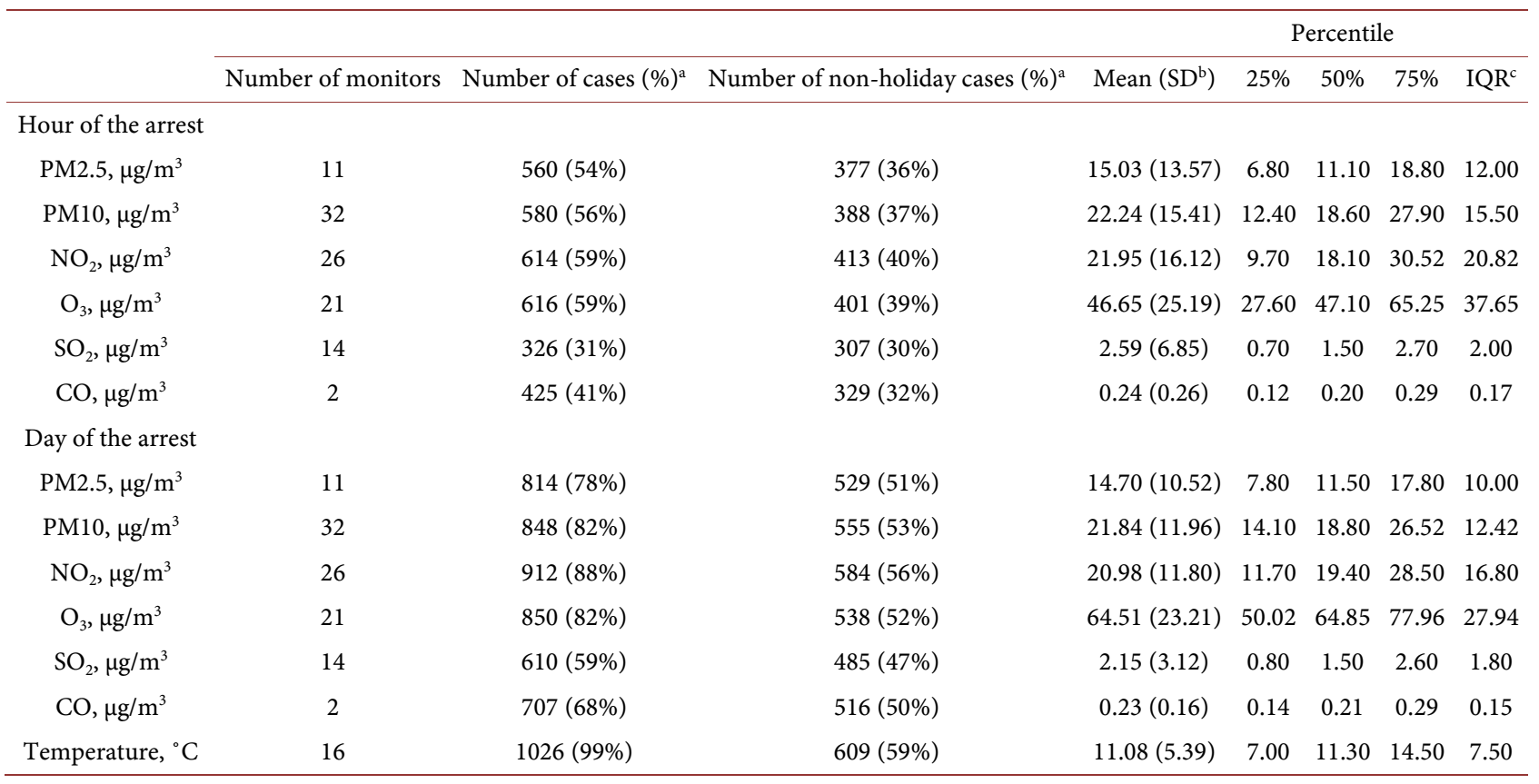

${ }^{\mathrm{a}}$ without missing values for the pollutant; ${ }^{\mathrm{b}}$ standard deviation; ' interquartile range.

Table 2. OR for OHCA in 2015 versus PM2.5 and PM10 exposures with single-pollutant models.

\begin{tabular}{|c|c|c|c|c|c|c|}
\hline \multirow[b]{2}{*}{ Lag } & \multicolumn{3}{|c|}{ PM2.5-Single-pollutant model } & \multicolumn{3}{|c|}{ PM10-Single-pollutant model } \\
\hline & Number of cases & OR per IQR (95\% IC) & $\mathrm{p}$ & Number of cases & OR per IQR (95\% IC) & $\mathrm{p}$ \\
\hline${\mathrm{Lag} 0 \mathrm{~h}^{\mathrm{a}}}$ & 551 & $0.99(0.90-1.09)$ & 0.836 & 571 & $1.06(0.95-1.17)$ & 0.313 \\
\hline $\mathrm{CA} 4 \mathrm{~h}^{\mathrm{b}}$ & 549 & $1.00(0.90-1.10)$ & 0.932 & 569 & $1.03(0.92-1.16)$ & 0.564 \\
\hline $\mathrm{CA} 12 \mathrm{~h}$ & 548 & $1.01(0.91-1.12)$ & 0.873 & 567 & $1.09(0.97-1.24)$ & 0.161 \\
\hline Lag0d ${ }^{c}$ & 804 & $0.97(0.89-1.06)$ & 0.542 & 835 & $1.03(0.93-1.13)$ & 0.577 \\
\hline $\operatorname{Lag} 1 d^{\mathrm{d}}$ & 807 & $1.00(0.92-1.09)$ & 0.985 & 835 & $1.03(0.93-1.13)$ & 0.564 \\
\hline Lag2d & 814 & $0.95(0.87-1.05)$ & 0.314 & 826 & $0.97(0.88-1.07)$ & 0.558 \\
\hline Lag3d & 812 & $1.03(0.94-1.12)$ & 0.562 & 825 & $0.98(0.89-1.08)$ & 0.671 \\
\hline Lag4d & 814 & $1.07(0.98-1.17)$ & 0.110 & 833 & $1.04(0.94-1.14)$ & 0.483 \\
\hline Lag5d & 816 & $0.99(0.91-1.08)$ & 0.847 & 838 & $0.98(0.89-1.07)$ & 0.642 \\
\hline
\end{tabular}

${ }^{a} \mathrm{Lag} 0 \mathrm{~h}$, exposure the hour of the arrest; ${ }^{\mathrm{b}} \mathrm{CA} 4 \mathrm{~h}$, average of lag0h to lag3h, etc.; $\mathrm{Clag} 0 \mathrm{~d}$, exposure the day of the arrest; ${ }^{\mathrm{d} l a g} 1 \mathrm{~d}$, exposure the day before the arrest, etc.

Table 3. OR for non-holiday OHCA versus PM2.5 with single- and multi-pollutant models.

\begin{tabular}{|c|c|c|c|c|c|c|}
\hline \multirow[b]{2}{*}{ Lag } & \multicolumn{3}{|c|}{ PM2.5-Single-pollutant model } & \multicolumn{3}{|c|}{ PM2.5-Multi-pollutant model } \\
\hline & Number of cases & OR per IQR (95\% IC) & $\mathrm{p}$ & Number of cases & OR per IQR (95\% IC) & $\mathrm{p}$ \\
\hline $\mathrm{Lag} \mathrm{h}^{\mathrm{a}}$ & 376 & $1.13(1.02-1.26)$ & 0.023 & 336 & $1.16(1.02-1.32)$ & 0.021 \\
\hline $\mathrm{CA} 4 \mathrm{~h}^{\mathrm{b}}$ & 376 & $1.15(1.02-1.29)$ & 0.023 & 337 & $1.16(1.01-1.34)$ & 0.038 \\
\hline $\mathrm{CA} 12 \mathrm{~h}$ & 374 & $1.17(1.03-1.32)$ & 0.016 & 329 & $1.18(1.01-1.39)$ & 0.043 \\
\hline $\operatorname{Lag} 0 \mathrm{~d}^{\mathrm{c}}$ & 527 & $1.12(1.02-1.24)$ & 0.019 & 198 & $1.01(0.81-1.26)$ & 0.946 \\
\hline $\operatorname{Lag} 1 d^{\mathrm{d}}$ & 540 & $1.07(0.97-1.18)$ & 0.206 & - & - & - \\
\hline Lag2d & 552 & $1.01(0.91-1.12)$ & 0.908 & - & - & - \\
\hline Lag3d & 534 & $1.08(0.98-1.18)$ & 0.124 & - & - & - \\
\hline Lag4d & 538 & $1.15(1.05-1.27)$ & 0.004 & 206 & $0.95(0.75-1.19)$ & 0.648 \\
\hline Lag5d & 531 & $1.08(0.97-1.19)$ & 0.151 & - & - & - \\
\hline
\end{tabular}


Table 4. OR for non-holiday OHCA versus PM10 with single- and multi-pollutant models.

\begin{tabular}{|c|c|c|c|c|c|c|}
\hline \multirow[b]{2}{*}{ Lag } & \multicolumn{3}{|c|}{ PM10-Single-pollutant model } & \multicolumn{3}{|c|}{ PM10-Multi-pollutant model } \\
\hline & Number of cases & OR per IQR (95\% IC) & $\mathrm{p}$ & Number of cases & OR per IQR (95\% IC) & $\mathrm{p}$ \\
\hline Lag0h & 386 & $1.21(1.07-1.37)$ & 0.002 & 353 & $1.25(1.08-1.44)$ & 0.003 \\
\hline CA4h & 389 & $1.20(1.05-1.37)$ & 0.006 & 353 & $1.24(1.07-1.45)$ & 0.006 \\
\hline $\mathrm{CA} 12 \mathrm{~h}$ & 384 & $1.33(1.15-1.55)$ & $<0.001$ & 343 & $1.38(1.15-1.66)$ & $<0.001$ \\
\hline Lag0d & 552 & $1.22(1.09-1.36)$ & $<0.001$ & 230 & $1.00(0.79-1.27)$ & 0.971 \\
\hline Lag1d & 560 & $1.10(0.98-1.23)$ & 0.106 & - & - & - \\
\hline $\operatorname{Lag} 2 \mathrm{~d}$ & 555 & $1.07(0.95-1.20)$ & 0.279 & - & - & - \\
\hline $\operatorname{Lag} 3 \mathrm{~d}$ & 547 & $1.07(0.95-1.19)$ & 0.263 & - & - & - \\
\hline Lag4d & 550 & $1.13(1.01-1.27)$ & 0.037 & 220 & $0.92(0.72-1.17)$ & 0.486 \\
\hline Lag5d & 545 & $1.11(0.99-1.24)$ & 0.084 & - & - & - \\
\hline
\end{tabular}

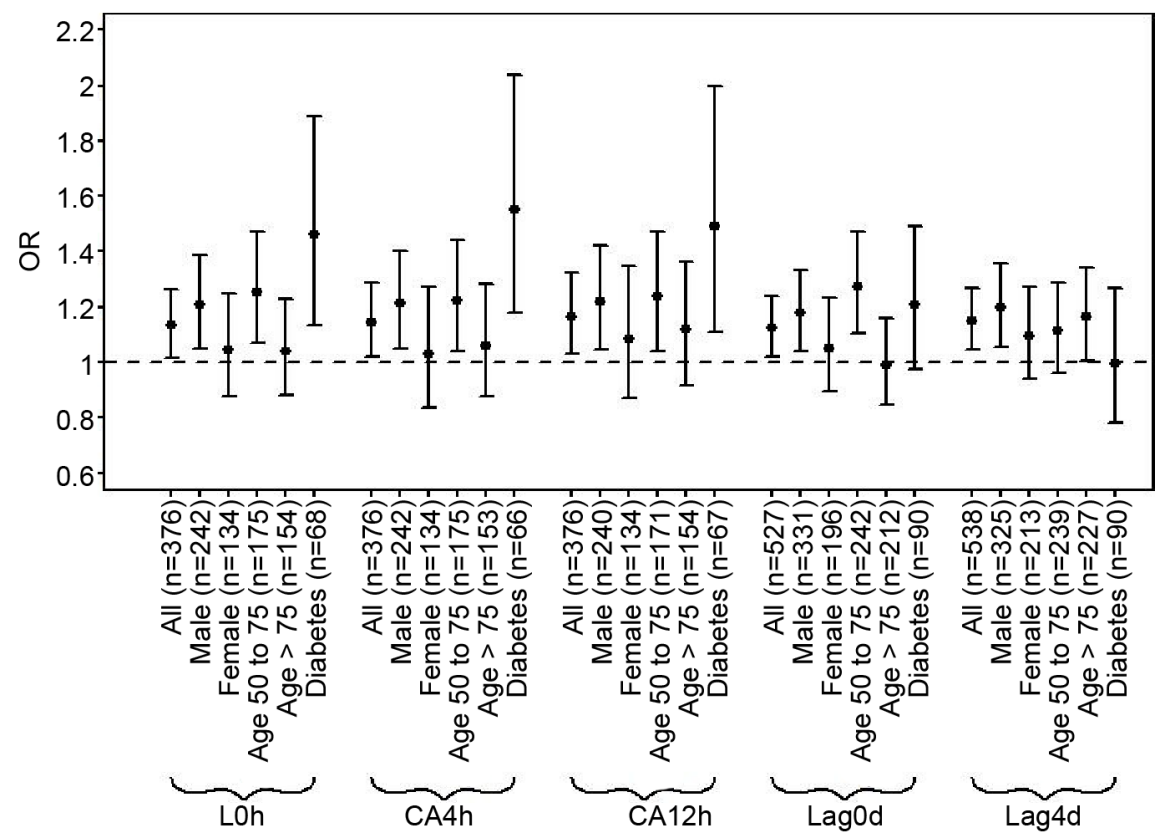

Figure 1. OR for non-holiday OHCA versus PM2.5 with subgroups in single-pollutant models.

at lag0d and lag4d with the smallest $\mathrm{p}$-value $(\mathrm{OR}=1.15, \mathrm{p}=0.004)$. The assessment of the association between non-holiday OHCA and PM10 (Table 4) showed significant associations at the same lags as for PM2.5 with the largest OR and the smallest $\mathrm{p}$-value in single-pollutant models at CA12h $(\mathrm{OR}=1.33, \mathrm{p}<$ $0.001)$.

In the following, for subgroup analyses, we describe single-pollutant models. The largest OR with the smallest p-values are mentioned at the hourly scale and at the daily scale.

Figure 1 reports OR for non-holiday OHCA versus PM2.5 exposures within subgroups in single-pollutant models. Within the subgroup men, we found the 


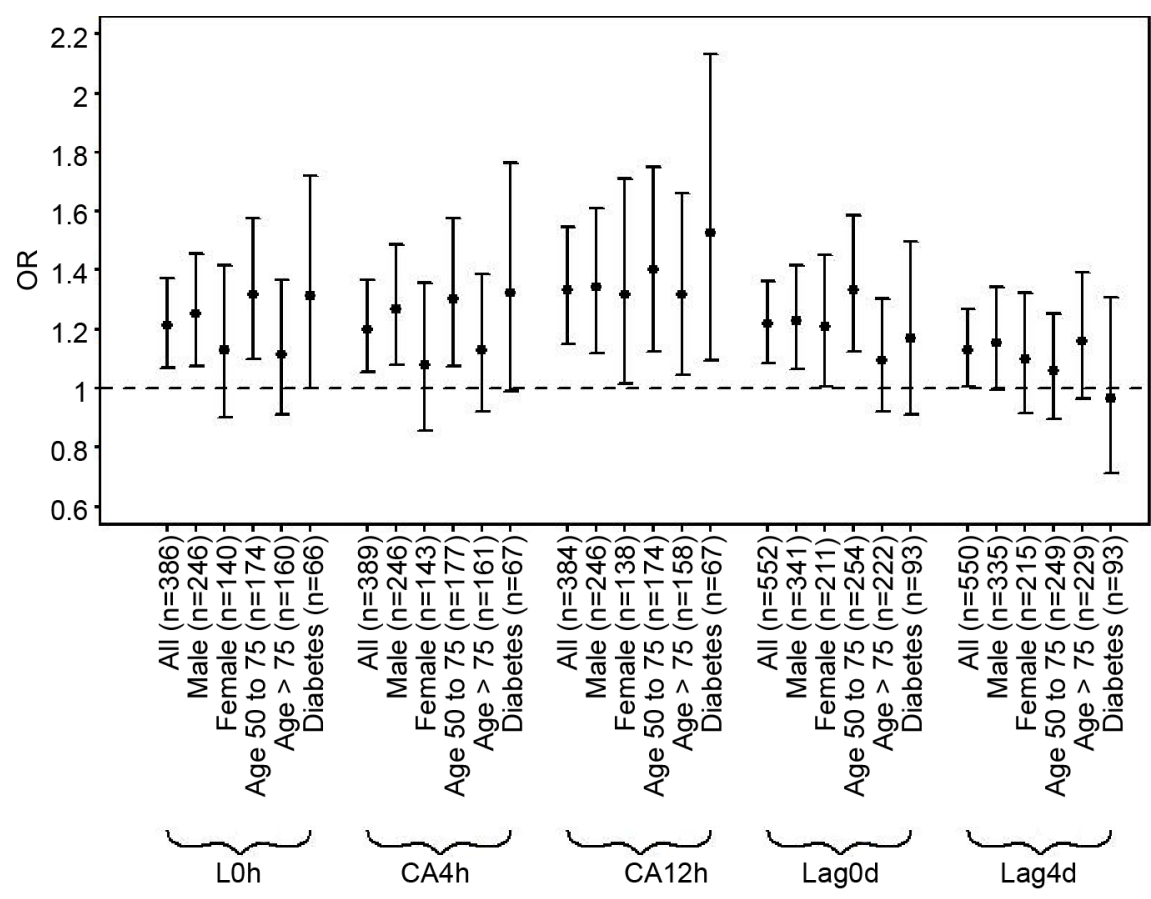

Figure 2. OR for non-holiday OHCA versus PM10 with subgroups in single-pollutant models.

same significant lag times: lag0h, CA4h $(\mathrm{OR}=1.21, \mathrm{p}=0.008), \mathrm{CA} 12 \mathrm{~h}, \operatorname{lag} 0 \mathrm{~d}$ and lag4d $(O R=1.20, p=0.005)$. No significant association was found in the subgroup women. In the age group 50 to 75 , OR were significant at lag0h $(\mathrm{OR}=$ $1.25, \mathrm{p}=0.005)$, CA4h, CA12h and lag0d (OR $=1.27, \mathrm{p}<0.001)$. Over 75 years old, only lag4d $(\mathrm{OR}=1.16, \mathrm{p}=0.041)$ showed a significant result. Within the subgroup with diabetes, larger OR were found with smaller $p$-values than the entire group, at lag0h, CA4h $(\mathrm{OR}=1.55, \mathrm{p}=0.002)$ and CA12h.

Figure 2 reports OR for non-holiday OHCA versus PM10 exposures within subgroups in single-pollutant models. Within the subgroup of men, OR were significant at lag0h, CA4h, CA12h $(\mathrm{OR}=1.34, \mathrm{p}=0.001)$ and lag0d $(\mathrm{OR}=1.23$, $p=0.005)$. Within the subgroup of women, OR were significant at CA12h $(O R=$ $1.32, \mathrm{p}=0.038)$ and lag0d $(\mathrm{OR}=1.21, \mathrm{p}=0.044)$. In the age group 50 to $75, \mathrm{OR}$ were significant at lag0h, CA4h, CA12h $(\mathrm{OR}=1.40, \mathrm{p}=0.003)$ and lag0d $(\mathrm{OR}=$ $1.33, \mathrm{p}=0.001)$. Over 75 years old, only CA12h $(\mathrm{OR}=1.32, \mathrm{p}=0.019)$ showed a significant result. Among patients with diabetes, $\mathrm{CA} 12 \mathrm{~h}(\mathrm{OR}=1.53, \mathrm{p}=0.013)$ showed significant OR.

\section{Discussion and Limitations}

\subsection{Discussion}

No significant association was revealed taking into account OHCA occurring all year long contrary to OHCA occurring during non-holiday periods. This may be explained by higher levels of particulate matter during non-holiday periods related to high traffic [23]. During the non-holiday periods, associations were 
found significant at the same lag times for PM2.5 and PM10 both at the hourly and daily scales (lag0h, CA4h, CA12h, lag0d, lag4d); this result is consistent with the fact that the levels of those pollutants are highly correlated. Larger OR with smaller p-values are found with PM10 compared to PM2.5. We have to be cautious interpreting this because there were more monitors measuring PM10 ( $\mathrm{n}=$ 32) than PM2.5 $(\mathrm{n}=11)$ possibly resulting in more reliable values reflecting individual exposures for PM10. However, lag4d was more significant with PM2.5 $(\mathrm{OR}=1.15, \mathrm{p}=0.004)$ than with PM10 $(\mathrm{OR}=1.13, \mathrm{p}=0.037)$ though multi-pollutant models did not give significant association for any of the daily lags. Significant results using multi-pollutant models are limited by correlation between pollutants which can result in over-fitting and masked effects. Analyses of non-holiday OHCA versus PM2.5 in subgroups men, age group 50 to 75 and diabetics generally showed larger OR with smaller p-values at the hourly scale (lag0h, CA4h, CA12h) and at lag0d for the first two subgroups.

In the literature, at the hourly scale, some studies found no significant association of PM2.5 or PM10 with OHCA [13] [16] [29]. A study found an association with the PM2.5 concentration during the hour of the OHCA, but only if this was witnessed by bystanders [30]. At the daily scale, some studies found significant positive associations between PM exposure (especially PM2.5) and OHCA with risk ranging from $2.4 \%$ to $13.6 \%$ per IQR increase in average PM exposure on the same day up to 4 days prior to the event [11] [12] [16] [17] [29]. An association was revealed with PM2.5 exposure measured 2 days before the arrest among current smokers with preexisting heart disease [14], while another study found no association between PM10 and OHCA [15]. In the literature, analyses according to subgroups brought out some significant results. Higher risks were found among men for PM2.5 [13] [16], among age groups under 75 [11] [16] [17] [30]; by contrast, no age effect was found in two studies [12] [13]. Among people with diabetes, a larger reduction of heart rate variability, which is a marker of cardiac autonomic control, was found [31] [32]. Short-term (at an hourly scale) and long-term (at a daily scale) associations found in our study are not mutually exclusive. PM could increase the risk of OHCA at three time scales: at a yearly scale by advancing atherosclerosis progression, at a daily scale by initiating or enhancing inflammatory processes in the lung and systemically and at an hourly scale by triggering ventricular dysrhythmia [13]. Particulate exposure may act on the autonomic nervous system to cause increase vulnerability to heart arrhythmias by increasing the incidence of ST-segment depression a marker of myocardial ischemia [33], by decreasing heart rate variability HRV a marker of cardiac autonomic control [34] [35] [36] [37], and by increasing heart rate [38], though the biological significance of this finding remains unclear. Particulate exposure may cause inflammation with an increase in blood coagulability increasing the risk for ischemic events [39] [40].

The results of this study could encourage public authorities to implement specific policy recommendations aimed at vulnerable subgroups (men, age group 50 
to 75 and diabetics) with specific public air quality systems or promote individual actions to reduce exposure (by limiting physical activity, staying indoors on high air pollution days, using cleaning indoor air with air filters...).

\subsection{Limitations}

The study found significant results over the non-holiday periods. We have to be cautious because we thus excluded holiday periods during which air pollution may act differently.

Multi-pollutant models used were adjusted on potential confounders $\mathrm{O}_{3}$ and $\mathrm{NO}_{2}$ but that could lead to improper models because of interactions or over-fitting (correlated pollutants). Indeed, toxicological studies reported that $\mathrm{O}_{3}$ may react with the surface of particles rendering them more biologically reactive [41], and $\mathrm{NO}_{2}$ is a marker of air pollution from local combustion sources (primarily motor vehicle traffic).

Interpretation of our results in a wider context is limited. Results are dependent of the study period, the number of monitors used (a small density can result in exposure misclassification), the area covered, sample size of cases, the designation of health end point, the comorbidities studied, the method of the pollution measurement, the composition of particulates, and the level of ambient concentration [30]. The imprecision of exposure estimates by using ATMO-NPdC monitors for the individual exposure measures for OHCA (that could occur indoors) can be considered non differential with respect to OHCA risk (the calculated OR would be underestimated). Nonetheless, strong correlations were found between indoor, outdoor, and personal levels of PM2.5 [42].

\section{Conclusion}

OHCA during non-holiday periods could be linked to particulate matter levels on the day and four days before the arrest. PM2.5 has more significant effects considering non-holiday OHCA within the subgroups men, age 50 to 75 years old and diabetics. Investigation of susceptible subgroups becomes especially important in epidemiological studies of PM because of the small population-wide relative risks that are usually observed. Studies in larger metropolitan areas with similar levels of air pollution may provide further insights into the risks and the factors associated with them and could lead to specific policy recommendations aimed at vulnerable subgroups. Further research is required to evaluate robustness of time-stratified case crossover focusing on non-holiday OHCA. As a final point, identification of potential confounders of air pollutants and ways to take them into account so as to provide the least bias models should be further explored.

\section{Acknowledgements}

We gratefully acknowledge the support and funding provided by the Heart and Arteries Foundation. 


\section{References}

[1] Hubert, H., Tazarourte, K., Wiel, E., Zitouni, D., Vilhelm, C., Escutnaire, J., Cassan, P., Gueugniaud, P.-Y., on Behalf of GR-RéAC (2014) Rationale, Methodology, Implementation, and First Results of the French Out-of-Hospital Cardiac Arrest Registry. Prehospital Emergency Care: Official Journal of the National Association of EMS Physicians and the National Association of State EMS Directors, 18, 511-519. https://doi.org/10.3109/10903127.2014.916024

[2] Chugh, S.S., Reinier, K., Teodorescu, C., Evanado, A., Kehr, E., Samara, M.A., Mariani, R., Gunson, K. and Jui, J. (2008) Epidemiology of Sudden Cardiac Death: Clinical and Research Implications. Progress in Cardiovascular Diseases, 51, 213 228. https://doi.org/10.1016/j.pcad.2008.06.003

[3] Gueugniaud, P.-Y., Bertrand, C., Savary, D. and Hubert, H. (2011) [Cardiac Arrest in France: Why a National Register?]. Presse Médicale (Paris, France: 1983), 40, 634-638. https://doi.org/10.1016/j.lpm.2011.02.026

[4] Krahn, A.D., Connolly, S.J., Roberts, R.S., Gent, M., ATMA Investigators (2004) Diminishing Proportional Risk of Sudden Death with Advancing Age: Implications for Prevention of Sudden Death. American Heart Journal, 147, 837-840.

https://doi.org/10.1016/j.ahj.2003.12.017

[5] GBD 2013 Risk Factors Collaborators, Forouzanfar, M.H., Alexander, L., Anderson, H.R., Bachman, V.F., Biryukov, S., Brauer, M., Burnett, R., Casey, D., Coates, M.M., et al. (2015) Global, Regional, and National Comparative Risk Assessment of 79 Behavioural, Environmental and Occupational, and Metabolic Risks or Clusters of Risks in 188 Countries, 1990-2013: A Systematic Analysis for the Global Burden of Disease Study 2013. Lancet (London, England), 386, 2287-2323.

https://doi.org/10.1016/S0140-6736(15)00128-2

[6] Bell, M.L., McDermott, A., Zeger, S.L., Samet, J.M. and Dominici, F. (2004) Ozone and Short-Term Mortality in 95 US Urban Communities, 1987-2000. JAMA, 292, 2372-2378. https://doi.org/10.1001/jama.292.19.2372

[7] Forastiere, F., Stafoggia, M., Picciotto, S., Bellander, T., D’Ippoliti, D., Lanki, T., von Klot, S., Nyberg, F., Paatero, P., Peters, A., et al. (2005) A Case-Crossover Analysis of Out-of-Hospital Coronary Deaths and Air Pollution in Rome, Italy. American Journal of Respiratory and Critical Care Medicine, 172, 1549-1555. https://doi.org/10.1164/rccm.200412-1726OC

[8] Peters, A., Dockery, D.W., Muller, J.E., and Mittleman, M.A. (2001) Increased Particulate Air Pollution and the Triggering of Myocardial Infarction. Circulation, 103, 2810-2815. https://doi.org/10.1161/01.CIR.103.23.2810

[9] Pope, C.A. and Dockery, D.W. (2006) Health Effects of Fine Particulate Air Pollution: Lines That Connect. Journal of the Air \& Waste Management Association, 56, 709-742.

[10] Brook, R.D., Rajagopalan, S., Pope, C.A., Brook, J.R., Bhatnagar, A., Diez-Roux, A.V., Holguin, F., Hong, Y., Luepker, R.V., Mittleman, M.A., et al. (2010) Particulate Matter Air Pollution and Cardiovascular Disease: An Update to the Scientific Statement from the American Heart Association. Circulation, 121, 2331-2378. https://doi.org/10.1161/CIR.0b013e3181dbece1

[11] Dennekamp, M., Akram, M., Abramson, M.J., Tonkin, A., Sim, M.R., Fridman, M., and Erbas, B. (2010) Outdoor Air Pollution as a Trigger for Out-of-Hospital Cardiac Arrests. Epidemiology (Cambridge, Mass.), 21, 494-500. https://doi.org/10.1097/EDE.0b013e3181e093db

[12] Silverman, R.A., Ito, K., Freese, J., Kaufman, B.J., De Claro, D., Braun, J. and Pre- 
zant, D.J. (2010) Association of Ambient Fine Particles with Out-of-Hospital Cardiac Arrests in New York City. American Journal of Epidemiology, 172, 917-923. https://doi.org/10.1093/aje/kwq217

[13] Wichmann, J., Folke, F., Torp-Pedersen, C., Lippert, F., Ketzel, M., Ellermann, T. and Loft, S. (2013) Out-of-Hospital Cardiac Arrests and Outdoor Air Pollution Exposure in Copenhagen, Denmark. PloS One, 8, e53684. https://doi.org/10.1371/journal.pone.0053684

[14] Sullivan, J., Ishikawa, N., Sheppard, L., Siscovick, D., Checkoway, H. and Kaufman, J. (2003) Exposure to Ambient Fine Particulate Matter and Primary Cardiac Arrest among Persons with and without Clinically Recognized Heart Disease. American Journal of Epidemiology, 157, 501-509. https://doi.org/10.1093/aje/kwg015

[15] Levy, D., Sheppard, L., Checkoway, H., Kaufman, J., Lumley, T., Koenig, J. and Siscovick, D. (2001) A Case-Crossover Analysis of Particulate Matter Air Pollution and Out-of-Hospital Primary Cardiac Arrest. Epidemiology (Cambridge, Mass.), 12, 193-199. https://doi.org/10.1097/00001648-200103000-00011

[16] Ensor, K.B., Raun, L.H. and Persse, D. (2013) A Case-Crossover Analysis of Out-ofHospital Cardiac Arrest and Air Pollution. Circulation, 127, 1192-1199.

https://doi.org/10.1161/CIRCULATIONAHA.113.000027

[17] Rosenthal, F.S., Kuisma, M., Lanki, T., Hussein, T., Boyd, J., Halonen, J.I. and Pekkanen, J. (2013) Association of Ozone and Particulate Air Pollution with Out-ofHospital Cardiac Arrest in Helsinki, Finland: Evidence for Two Different Etiologies. Journal of Exposure Science \& Environmental Epidemiology, 23, 281-288. https://doi.org/10.1038/jes.2012.121

[18] Levy, D., Lumley, T., Sheppard, L., Kaufman, J. and Checkoway, H. (2001) Referent Selection in Case-Crossover Analyses of Acute Health Effects of Air Pollution. Epidemiology (Cambridge, Mass.), 12, 186-192. https://doi.org/10.1097/00001648-200103000-00010

[19] Cummins, R.O., Chamberlain, D.A., Abramson, N.S., Allen, M., Baskett, P.J., Becker, L., Bossaert, L., Delooz, H.H., Dick, W.F. and Eisenberg, M.S. (1991) Recommended Guidelines for Uniform Reporting of Data from Out-of-Hospital Cardiac Arrest: The Utstein Style. A Statement for Health Professionals from a Task Force of the American Heart Association, the European Resuscitation Council, the Heart and Stroke Foundation of Canada, and the Australian Resuscitation Council. Circulation, 84, 960-975. https://doi.org/10.1161/01.CIR.84.2.960

[20] Maclure, M. (1991) The Case-Crossover Design: A Method for Studying Transient Effects on the Risk of Acute events. American Journal of Epidemiology, 133, 144153. https://doi.org/10.1093/oxfordjournals.aje.a115853

[21] Lumley, T. and Levy, D. (2000) Bias in the Case-Crossover Design: Implications for Studies of Air Pollution. Environmetrics, 11, 689-704.

https://doi.org/10.1002/1099-095X(200011/12)11:6<689::AID-ENV439>3.0.CO;2-N

[22] Janes, H., Sheppard, L. and Lumley, T. (2005) Case-Crossover Analyses of Air Pollution Exposure Data: Referent Selection Strategies and Their Implications for Bias. Epidemiology, 16, 717-726. https://doi.org/10.1097/01.ede.0000181315.18836.9d

[23] Tan, P.-H., Chou, C., Liang, J.-Y., Chou, C.C.-K. and Shiu, C.-J. (2009) Air Pollution "Holiday Effect" Resulting from the Chinese New Year. Atmospheric Environment, 43, 2114-2124. https://doi.org/10.1016/j.atmosenv.2009.01.037

[24] Basu, R. and Samet, J.M. (2002) Relation between Elevated Ambient Temperature and Mortality: A Review of the Epidemiologic Evidence. Epidemiologic Reviews, 24, 190-202. https://doi.org/10.1093/epirev/mxf007 
[25] Braga, A.L., Zanobetti, A. and Schwartz, J. (2001) The Time Course of Weather-Related Deaths. Epidemiology, 12, 662-667. https://doi.org/10.1097/00001648-200111000-00014

[26] Curriero, F.C., Heiner, K.S., Samet, J.M., Zeger, S.L., Strug, L. and Patz, J.A. (2002) Temperature and Mortality in 11 Cities of the Eastern United States. American Journal of Epidemiology, 155, 80-87. https://doi.org/10.1093/aje/155.1.80

[27] Stafoggia, M., Forastiere, F., Agostini, D., Biggeri, A., Bisanti, L., Cadum, E., Caranci, N., de'Donato, F., De Lisio, S., De Maria, M., et al. (2006) Vulnerability to Heat-Related Mortality: A Multicity, Population-Based, Case-Crossover Analysis. Epidemiology, 17, 315-323. https://doi.org/10.1097/01.ede.0000208477.36665.34

[28] Eilers, P.H.C. and Marx, B.D. (1996) Flexible Smoothing with B-Splines and Penalties. Statistical Science, 11, 89-121. https://doi.org/10.1214/ss/1038425655

[29] Straney, L., Finn, J., Dennekamp, M., Bremner, A., Tonkin, A. and Jacobs, I. (2014) Evaluating the Impact of Air Pollution on the Incidence of Out-of-Hospital Cardiac Arrest in the Perth Metropolitan Region: 2000-2010. Journal of Epidemiology and Community Health, 68, 6-12. https://doi.org/10.1136/jech-2013-202955

[30] Rosenthal, F.S., Carney, J.P. and Olinger, M.L. (2008) Out-of-Hospital Cardiac Arrest and Airborne Fine Particulate Matter: A Case-Crossover Analysis of Emergency Medical Services Data in Indianapolis, Indiana. Environmental Health Perspectives, 116, 631-636. https://doi.org/10.1289/ehp.10757

[31] Park, S.K., O’Neill, M.S., Vokonas, P.S., Sparrow, D. and Schwartz, J. (2005) Effects of Air Pollution on Heart Rate Variability: The VA Normative Aging Study. Environmental Health Perspectives, 113, 304-309. https://doi.org/10.1289/ehp.7447

[32] Whitsel, E.A., Quibrera, P.M., Christ, S.L., Liao, D., Prineas, R.J., Anderson, G.L. and Heiss, G. (2009) Heart Rate Variability, Ambient Particulate Matter Air Pollution, and Glucose Homeostasis: The Environmental Epidemiology of Arrhythmogenesis in the Women's Health Initiative. American Journal of Epidemiology, 169, 693-703. https://doi.org/10.1093/aje/kwn400

[33] Pekkanen, J., Peters, A., Hoek, G., Tiittanen, P., Brunekreef, B., de Hartog, J., Heinrich, J., Ibald-Mulli, A., Kreyling, W.G., Lanki, T., et al. (2002) Particulate Air Pollution and Risk of ST-Segment Depression during Repeated Submaximal Exercise Tests among Subjects with Coronary Heart Disease: The Exposure and Risk Assessment for Fine and Ultrafine Particles in Ambient Air (ULTRA) Study. Circulation, 106, 933-938. https://doi.org/10.1161/01.CIR.0000027561.41736.3C

[34] Magari, S.R., Schwartz, J., Williams, P.L., Hauser, R., Smith, T.J. and Christiani, D.C. (2002) The Association between Personal Measurements of Environmental Exposure to Particulates and Heart Rate Variability. Epidemiology, 13, 305-310. https://doi.org/10.1097/00001648-200205000-00011

[35] Gold, D.R., Litonjua, A., Schwartz, J., Lovett, E., Larson, A., Nearing, B., Allen, G., Verrier, M., Cherry, R. and Verrier, R. (2000) Ambient Pollution and Heart Rate Variability. Circulation, 101, 1267-1273. https://doi.org/10.1161/01.CIR.101.11.1267

[36] Liao, D., Creason, J., Shy, C., Williams, R., Watts, R. and Zweidinger, R. (1999) Daily Variation of Particulate Air Pollution and Poor Cardiac Autonomic Control in the Elderly. Environmental Health Perspectives, 107, 521-525. https://doi.org/10.1289/ehp.99107521

[37] Pope, C.A. 3rd, Verrier, R.L., Lovett, E.G., Larson, A.C., Raizenne, M.E., Kanner, R.E., Schwartz, J., Villegas, G.M., Gold, D.R. and Dockery, D.W. (1999) Heart Rate Variability Associated with Particulate Air Pollution. American Heart Journal, 138, 890-899. https://doi.org/10.1016/S0002-8703(99)70014-1 
[38] Pope 3rd, C.A., Dockery, D.W., Kanner, R.E., Villegas, G.M. and Schwartz, J. (1999) Oxygen Saturation, Pulse Rate, and Particulate Air Pollution: A Daily Time-Series Panel Study. American Journal of Respiratory and Critical Care Medicine, 159, 365-372. https://doi.org/10.1164/ajrccm.159.2.9702103

[39] Baccarelli, A., Zanobetti, A., Martinelli, I., Grillo, P., Hou, L., Giacomini, S., Bonzini, M., Lanzani, G., Mannucci, P.M., Bertazzi, P.A., et al. (2007) Effects of Exposure to Air Pollution on Blood Coagulation. Journal of Thrombosis and Haemostasis. JTH, 5, 252-260. https://doi.org/10.1111/j.1538-7836.2007.02300.x

[40] Pekkanen, J., Brunner, E.J., Anderson, H.R., Tiittanen, P. and Atkinson, R.W. (2000) Daily Concentrations of Air Pollution and Plasma Fibrinogen in London. Occupational and Environmental Medicine, 57, 818-822. https://doi.org/10.1136/oem.57.12.818

[41] Bosson, J., Pourazar, J., Forsberg, B., Adelroth, E., Sandström, T. and Blomberg, A. (2007) Ozone Enhances the Airway Inflammation Initiated by Diesel Exhaust. Respiratory Medicine, 101, 1140-1146. https://doi.org/10.1016/j.rmed.2006.11.010

[42] Janssen, N.A., Lanki, T., Hoek, G., Vallius, M., de Hartog, J.J., Van Grieken, R., Pekkanen, J. and Brunekreef, B. (2005) Associations between Ambient, Personal, and Indoor Exposure to Fine Particulate Matter Constituents in Dutch and Finnish Panels of Cardiovascular Patients. Occupational and Environmental Medicine, 62, 868-877. https://doi.org/10.1136/oem.2004.016618 